\title{
A space has been made: bisexual+ stories in musical theatre
}

(additional items for this article: a Spotify playlist; embeddable Youtube video 'Give Me a Label'; art work specifically made for this - the bisexual flag and Alexander Hamilton by Mat Dalgleish)

It is 2018, and I am sitting in the Neptune Theatre, Halifax, Canada. I'm watching the Canadian premiere of The Color Purple directed by Kimberley Rampersad (the first time the show has been directed by a black woman). It is the first ever positive representation of my own sexuality that I have seen in the form which I have spent almost two decades studying, researching and writing about. As I see the character of Shrug Avery (Karen Burthwright) delight in the fluidity of her own sexual desire, a desire above and beyond gender, it feels like a space has been made. I'm crying but it's complicated. Joy? Sadness? Recognition?

I am writing from the perspective of a bisexual+ cis-gendered white British woman, so it is important to note the many kinds of priviledge that shape the experiences I am talking about, especially when addressing this musical. The Color Purple (2005) is especially important in the space it makes for PoC, and Women of Colour. This has been written about both in reference to the musical (Lovelock, Edney) and the novel (Bealer); and by Alice Walker herself (Walker). For me, it is the first time I have seen what it is to be bisexual on a stage, while I recognise that this musical does many more important things than that in connection to race and sexuality, its powerful story makes ripples.

In June 2000, about a month after I finished my secondary education in a small school in mid-Wales, Section 28 repealed, first in Scotland, and three years later in the rest of the UK. I'd like to say I remember it, but I don't. If I even knew about it at the time, it would have been because my parent's copy of The Daily Mail was Cross and Appalled. It was almost always cross and/or appalled though, so it doesn't stick out in my memory. I don't even remember when I first heard the word bisexuality. It certainly wouldn't have been at school, because Section 28 had made it illegal for schools to discuss LGBTQ+ lifestyles because it would risk promoting them. The teaching of the 'acceptability of homosexuality' was explicitly forbidden by Section 28 from 1988 to 2000: bisexuality was not even mentioned (Local Government Act).

Even in my early 20s, when I joined a dating site and ticked 'interested in men and women', I still didn't really identify as bisexual because I don't think I even understood that was ever an option for me. Bisexuals were the people who hadn't made up their minds... right? And then to cap it all off, I fell in love with a man who I married within a year of meeting, so I had to hand in my badge of not quite knowing how I fitted in. Some fifteen years later, I'm still married to him, and my relationship has given me huge amounts of privileges (we could get married, when if I'd have fallen in love with a woman at the same time, we would have waited until 2014 to do the same, if I'd have fallen in love with a non-binary person, we still 
could not in a way that recognised both of our gender identities). But despite these many privileges that I have clearly benefited from, my innate queerness did not simply go away.

Late June 2016. I am at the Circle in the Square Theatre, New York, watching Beth Malone and Michael Cerveris in Fun Home play the characters of Alison Bechdel and her father in a car. The mass murder at Pulse Nightclub, an LGBTQ+ hatecrime targetted at the Latinx community, took place on June 12th. Everything hangs heavy in the air. That week I had stood behind a cordon, watching the Pride March being led by elders in the community, carrying photographs of the 49 victims.

Like many of the queer people in the audience of Fun Home, I cried, heaving sobs. When the house lights come back on, the theatre is full of red-eyed people who get it, nodding in encouragement.

It is September 2016 and I try saying the words in front of classes about studying sexuality in musical theatre studies: 'I'm speaking as a bisexual woman'. After one of these classes a student excitedly approaches me and says 'you're the first ever bi grown up I've ever met in real life!' All of this matters: and it keeps mattering. I was encouraged by a colleague, a lecturer who as a gay man advocates for LGBTQ+ student experiences. At the LGBTQ+ research group that he runs, I heard depressingly similar school experiences from students finishing school twenty years after I did, and after the end of Section 28. There are some more positive ones, but with the difference that these undergraduates know the word bisexuality, in a way I did not in 2000.

Each time I repeated the words, I became more convinced that not only is being bisexual part of my identity, but more importantly, being out as a bisexual could be a positive experience for all my students and especially my LGBTQ+ ones. To be clear, bisexuality+ is used as an overarching term for a group of named descriptions which people may use to communicate their identity: one of the most used of these terms is pansexual. All of these terms suggest a person who is attracted to people of more than one gender - who are in effect not monosexual (attracted to one gender). This broader definition responds to theorist Surya Monro's usage of the word bisexual as a 'strategic move that overlooks the binary composition of the word' (Monro, 2). In the UK in 2020, the Office of National Statistics found that people aged 16 to 24 are more likely to identify as lesbian, gay or bisexual than any other age group, but with a larger percentage of the popular (2.8\%) identifying as bisexual than the smaller group (1.6\%) identifying as gay or lesbian. In my own age bracket only $0.6 \%$ of people identify as bisexual (35-49).

Despite what is a growing identification with bisexuality + to name our sexual identities, myths and misconceptions about bisexuality continue to shape how the ' $\mathrm{B}$ ' in the LGBTQ+ identities are represented in popular culture. Bisexuals are confused, 'halfway to gay', promiscuous, greedy... I mean, some of us might be, I can't be left alone with a selection box. But chocolates are not people. 


\section{Invisible bisexuality in musicals: from 2000 to 2020}

While all LGBTQ+ people suffer from 'minority stress' (Meyer), bisexuals have a uniquely poor experience of experiencing distrust from heterosexual and homosexual community (Brewster and Moradi). One major Australian study notes the widespread and 'consistent evidence that bisexual people have poorer mental health than heterosexual people, gay men or lesbians' (Taylor et al): this also has been addressed in terms of intersectional oppressions (Dyar et al). The invisibility of bisexuality in popular culture has very real consequences to an oppressed community.

Maria San Filipo, in her important study of representations of bisexuality in popular culture, argues that the sexuality is 'both visible and invisible':

[...] due to the slippage between its representational pervasiveness and the alternating measures of tacit acceptance, disidentification, or disavowal that render bisexuality discursively un(der)spoken. (San Filipo, 4)

'Mainstream' musicals, that is to say Broadway and West End commercially orientated musicals, have tended to minimise bisexual content even in material which openly acknowledges bisexual desire. Just as Steven Spielberg's movie adaptation of The Color Purple (1985) removes the bisexual utopian possibility from Alice Walker's 1982 novel; several productions of the musical since its 2005 premiere have emphasised the relationship between Shug and Celie as that of sisters. Bisexuality is, as San Filipo contends, rendered underspoken.

The removal of bisexual desire is common in musicals, even in that contemporary behemoth, Hamilton (2015). Lin-Manuel Miranda's musical Hamilton may not look or sound like the mega musicals of the 1980s, but its success echoes the scale of the phenomenon of shows like Cats (1981) and Les Misérables (1985). Hamilton is based on Ron Chernow's 2004 biography of its eponymous politician, the first treasurer of the United States and prolific writer and thinker. The musical uses traditional Broadway storytelling to dramatise the struggle between two men, Alexander Hamilton and Aaron Burr, who are trapped in personal and political rivalries. Hamilton owes a notable debt to Les Mis, since both shows tell epic stories about two men locked in a conflict which will only be resolved by one of them dying. Just as in Les Miserables where we see Valjean and Javert's moral battle play out over the decades condensed into two acts, admittedly quite long ones; Hamilton traces two men's respective rise and fall over a thirty year period. The main tension is not in the will they/won't they of a romance or sexual tension, but rather in the unfolding of the two men's relationship which the audience already know will end in disaster.

Of course, there is a straight love story in the musical, the marriage between Eliza Schuyler and Alexander, and his attachment to her sister (presented as his intellectual equal). However, there is another love story which is barely noticeable in the musical, albeit it something

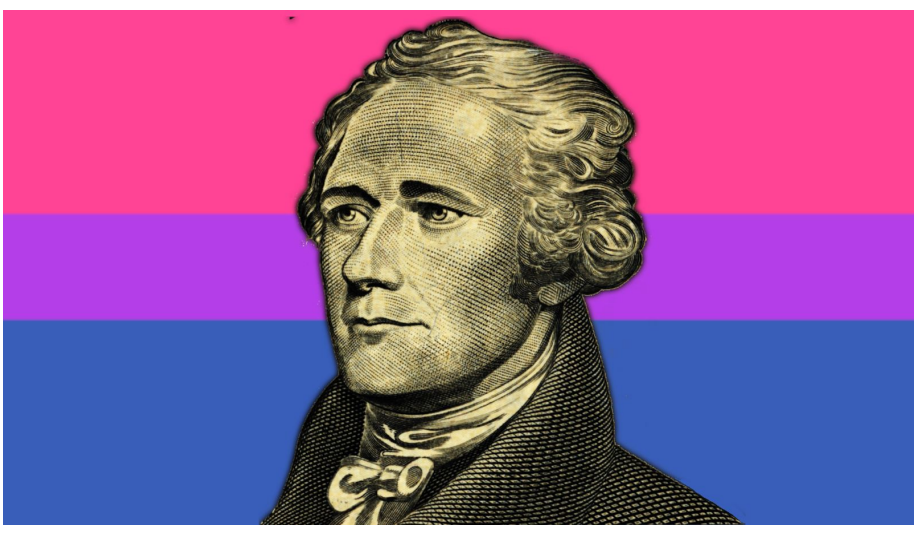


that bisexual fan communities have responded to. The physical and emotional attraction between Hamilton and his close friend, and fellow aide-de-camp to George Washington, John Laurens. Their friendship is documented in letters which have been the focus of discussion about their potential for a romantic or sexual relationship between the two men. Clearly, the possibility of a bisexual character in this musical offers the tantalising possibility of putting us in 'The Room Where it Happens' at the centre of a Broadway musical. It is clearly ahistorical to suggest that such physical or emotional desire would have made a person identify as bisexual in the mid-18th century. However, Hamilton's 'bisexual identity' has been given the authority of the author of the musical.

Lin-Manuel Miranda, the composer, lyricist and performer behind the musical, is a celebrity in his own right, with an extensive social media presence and around 3 million followers on Twitter: something he uses both for social activism and musical theatre nerdery. He is essentially a hero for musical theatre geeks everywhere. In 2015, when doing an impromptu $\mathrm{Q}$ and A with his followers while waiting at an airport for a connection, Miranda responded to a question about whether he thought Hamilton could have 'maybe been bi' - by replying 'Yeah. Read those letters man' (Miranda). For bisexual people this is a complex feeling: because to be seen and at the same time not seen, really hurts. Despite the throwaway nature of tweets in general, never mind tweets sent at airport lounges in one-off $Q$ and $A^{\prime}$ s, the complete disregard of how it actually feels to be bisexual and to be constantly outside of the story is painful. The creator of a cultural phenomenon, which will be around for decades to come, says "yes Hamilton was bisexual" but that is not included in the musical itself. There is more to say here in staging of Laurens and Hamilton and the argument that it does show some kind of love story, however this is something I'm currently writing on at more length elsewhere (forthcoming). For now, I wanted to consider the stakes of erasure in comparison to musicals which do actually feature prominently bisexual characters. Because, when people say '\#representationmatters' it can feel easy to dismiss as a stereotype of keyboard activists. But to have the tantalising possibility of being seen and understood in the form of theatre you love the most, and for it not to happen... It breaks my heart.

\section{Problematic representations:}

There are bisexuals in musical theatre, it's just that many musicals have featured them through well worn tropes about bisexuals. The dangerously detailed TvTropes lists a number of tropes around bisexuality that also appear in musicals; 'Depraved Bisexuality' (the bisexual villain); ' Anything that Moves' (the greedy bisexual); 'Suddenly-Sexuality' or perhaps the rarest trope, 'Bi-the-Way' (a character whose bisexuality is incidental to the story).

'Anything-that-moves' as a trope has underpinned many bisexual representations in musicals. While this might be an accurate representation for some bisexuals, we are not inherently non-monogamous and/or insatiable. It has also been used to imply that bisexuality is indicative of sexual impropriety - of a society or culture which does not have tight moral controls on who can have sex with whom. In these sorts of things it is possible to see instances of bisexuality, but rather than detailed characters, they are generally being used as a shorthand to quickly communicate that extreme-sexual-excess-happens-here. 
Perhaps the most famous example of this is The Rocky Horror Picture Show (1973) through the medium of a sci-fi B-movie style musical, presents a radical version of relaxed sexual behaviour. Although in the musical Frank ' $n$ ' Furter could be read as a 'depraved bisexual', it's worth bearing in mind he is also an alien who gets vaporised by another alien at the end of the musical (by Riff Raff). His desire for humans, specifically for the buttoned up all-American preppy innocents Janet and Brad, is part of the musical's broader representation of sexual excess, rather than any detailed representation of bisexuality. However - it is worth noting that Richard O'Brien, who wrote the book, music and lyrics of the musical, identifies as bisexual, and has explained that he used the aliens purposefully to show the exclusion of non-heterosexual and heteronormative people. (Jones)

Some productions of Cabaret (1966) have similarly used bisexuality to indicate times of sexual freedom: the musical is set in the last days of the Weimar Republic, in Berlin. In all versions of the story, there is a character who acts as an audience conduit, the writer originally Cliff, and renamed Brian for the movie. He shows us into this simultaneously glamorous, depraved and dangerous world. The author of the semi-autobiographical memoirs the musical is based on, Christopher Isherwood, was a gay man. However, in both the 1972 movie and the 1993 Broadway revival directed by Sam Mendes, the Cliff/Brian character is explicitly bisexual. Cliff's importance to the overall story is fairly minimal, reviewer Ben Brantley wrote he 'remains one of those artist-as-cipher characters that it's hard to do much with.' (Brantley). Bisexuality in Cabaret demonstrates the anything goes culture of the setting, again, rather than being really central to the plot.

In Jonathan Larson's rock musical Rent (1994), the then edgy cast of characters includes the 'Anything-that-moves' kind of bisexual, Maureen. Maureen never explicitly identifies as bisexual, we are just told she has had many relationships with men and women. In fact, this is one of the first things we know about her, because we hear about it before we even meet her, through the frustrations of her current girlfriend Joanne (Fredi Walker) and her ex-boyfriend Mark (Anthony Rapp). Together, they sing the 'Tango: Maureen', expressing jealous frustration at Maureen's sexual antics, setting up our expectations for a character who is both an untrustworthy nightmare and a diva. We are told she cannot be content in a monogamous relationship: both Mark and Maureen complain about her cheating. When Maureen (Idina Menzel) does appear, and sings about her relationship in 'Take Me or Leave

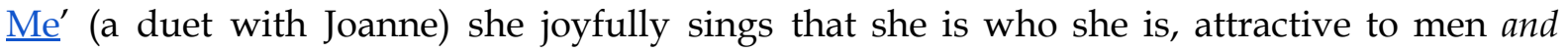
women. While bisexuality is not named - she fulfils the trope of the greedy bisexual who will inevitably break the hearts of those who love her, because she is incapable of monogamy. Whether this is due to Maureen's character, or her sexuality is not exactly cleared up. Though, the fact Maureen and Joanne are allowed a relationship in a 1994 musical is an important step forward.

\section{Towards positive role models and better representations?}

Part of the problem is that showing multiple kinds of sexual desire either requires a direct mention in the plot, perhaps some kind of coming out song, or the inclusion of sexual attraction to people of more than one gender in the story. The musical If/Then (2014) has the perfect structure for representing bisexuality in its 'what-if' story, which runs two simultaneous timelines in Elizabeth's life (also played by Idina Menzel). In one timeline, the 
character of Lucas has a relationship with a woman, and in the other with a man. The casting calls to Rent since Lucas is played by Anthony Rapp (the original Mark) and Elizabeth by Menzel. Elizabeth is dismissive of Lucas's sexuality, telling him that it's equivalent to being a political independent. However, Lucas does get to have loving relationships in both timelines, and he addresses his own bisexuality in 'Some Other Me': 'I found myself a woman, or a man, and had a son.' Again, it's not perfect, but it is some kind of representation.

Being bisexual doesn't mean that your love story is necessarily complicated or tragic. You don't have to have had lots of relationships, or even have had sex with people of other genders to qualify. To be representative musicals don't have to portray some kind of tangled or torrid affair - they have to include bisexual characters as part of the story, and those characters should have believable inner lives. It should not be a throwaway joke either, as in Be More Chill's final scenes which makes bisexuality 'the butt of the joke' (Clarke); or in Groundhog Day with Phil's throwaway gag that he was so bored in his endless day in Punxsutawney, he slept one time with a guy.

There are more positive bisexual characters in contemporary television from the same period, however these roles can be limited. Meyer notes that characters like Callie Torres (Grey's Anatomy) and Anna Tagaro (One Tree Hill) bisexual women of color 'serve to stabilize heterosexuality and open discourse for White characters.' (Meyer 375) One important exception to this may be the sensitive way in which Brooklyn 99 worked with bisexual cast member Stephanie Beatriz, to show the character she plays, Rosa Diaz, coming out as bi to her colleagues: she reflected that 'the main thing for me was that the character said "bisexual" and that she said it so many times.' (Beatriz in Jung) Bisexual characters where their sexual identity are part but not all of their story are becoming more prominent in television; Eleanor Shellstrop in The Good Place, Adam in Jane the Virgin, and Toni Topaz and Cheryl Blossom in Riverdale.

Television musicals have written inclusive bisexual stories: Crazy Ex-Girlfriend includes three bisexual characters, Maya, Valencia Perez and Darryl Whitefeather. While Darryl does sing the fantastic coming out number 'Getting Bi', Maya mentions in passing during that song that she is also bisexual, and Valencia is seen in relationships with men and women. Some musicals bridge this genre gap, for example the YouTube and stage success Team Starkids, with Firebringer which characters with sexually fluid desires.

Stage musicals are starting to shift to create more accurate representations. Bare: A Musical (2012) reflects a teenage experience of sexuality, and can be read as coming to terms with being bisexual, through Jason's song 'Once Upon a Time' and 'A Role of a Lifetime'. This is particularly notable because this potential bisexual reading is an addition, since the musical is a revision of the earlier Bare: A Pop Opera (2000) in which Jason is closeted as gay, but in a relationship with a woman. More recently, $\mathcal{E}$ Juliet (2019), currently in the West End, features Francois who is pansexual, as a central character and love interest for Juliet, who has survived her escapades with Romeo. Writer Max Martin explained that it was really important to me that our cast of characters reflect the diversity of the world around us as 
much as possible, and that included gender, age, body type, ethnicity, and sexual orientation.' (Martin in Connelly).

It's March 2020 and new musical theatre events are quickly being cancelled, years of work on pause for a while as the UK arts scene is on lockdown, as we all stay safe indoors at home. Last month, though it feels like a lifetime ago, my students performed at an LGBTQ+ concert at the University of Wolverhampton. Some of them sang their own work as in the case of Abbie Cobden who sang a song from a musical she is writing called 'Give Me a Label' (music by James Lovelock), and they have kindly agreed to share it here.

[Embedded Youtube link - html for this available here -

https://wwww.youtube.com/watch?v=fp98q0EOYAA]

Into the space where there were so few stories, and so few representations of bisexuality much is changing quickly, and queer stories are taking centre stage, importantly many of these stories centre QPoC. Two new musicals in development of note include, Interstate by Kit Yan and Melissa Li which features queer and trans characters; and Asian Pirate Musical by Nemo Martin and Zhui Ning Chang with its queer space revolutionaries.

There are two bisexual and pan characters in the exciting The Phase musical, written by Meg McGrady and Zoe Elle Morris, which was meant to have a showing at BEAM2020 (the event was cancelled because of Covid-19). You can learn about its development in this video to its song 'Sex Education'. Twenty years after I left school, the song still references that Section 28 is no longer in effect, but as the character acknowledges 'Not legally but that doesn't mean we don't see its effects' (McGrady and Morris, 2020). As new musicals tell better stories about the bisexual community, each moment of inclusion still matters and makes a space for the next.

\section{Acknowledgements}

Thanks to Meg McGrady, Joe Geoghan, Abbie Cobden, James Lovelock, Nemo Martin, Mat Dalgleish, Emily Beaman, Joash Musundi, Kirsty Sedgman and Emily Garside.

\section{Works Cited}

Bealer, Tracy L. “Making Hurston's Heroine Her Own: Love and Womanist Resistance in The Color Purple." Alice Walker's The Color Purple. Brill Rodopi, 2009. 23-42.

Brantley, Ben. “THEATER REVIEW; Desperate Dance at Oblivion's Brink.” The New York Times, 20 Mar. 1998, [online], 
www.nytimes.com/1998/03/20/movies/theater-review-desperate-dance-at-oblivion-sbrink.html. Accessed 20 Aug. 2018.

Brewster, Melanie E., and Moradi, Bonnie. “Perceived Experiences of Anti-Bisexual Prejudice: Instrument Development and Evaluation." Journal of Counseling Psychology, vol. 57, no. 4, 2010, pp. 451-68, doi:10.1037/a0021116.

Clarke, David. “Musical Adaptation for 'Be More Chill' Is Fun, But Troubled." Out, 13 Mar. 2019, https://www.out.com/theater/2019/3/13/be-more-chill-broadway-review. Accessed 13 Mar. 2020.

Connelly, William J. “E Juliet Is Max Martin’s New Musical Boldly Giving Queer People a Voice." Gay Times, 13 Nov. 2019, www.gaytimes.co.uk/culture/129289/juliet-is-max-martins-new-musical-boldly-giving -queer-people-a-voice. Accessed 14 Mar. 2020.

Dyar, C., Taggart, T. C., Rodriguez-Seijas, C., Thompson, R. G., Elliott, J. C., Hasin, D. S., \& Eaton, N. R. “Physical Health Disparities Across Dimensions of Sexual Orientation, Race/Ethnicity, and Sex: Evidence for Increased Risk Among Bisexual Adults." Archives of Sexual Behavior. vol. 48, no. 1. 2018. pp. 225-242. doi:10.1007/s10508-018-1169-8.

Edney, Kathryn. "Adapting and Integrating: The Color Purple as Broadway Musical”. Adapting and Integrating: The Color Purple as Broadway Musical. Leiden, The Netherlands: Brill | Rodopi, 2009. https://doi.org/10.1163/9789042028913 013.

Jones, M. F. “Richard O’Brien: Lucky Man.” Exeunt Magazine, 10 Jan. 2013, http:// exeuntmagazine.com/features/richard-obrien. Accessed 28 March 2020.

Jung, E. Alex. “Stephanie Beatriz's Bisexual Awakening, Onscreen and Off." Vulture, 21 May 2018, 
www.vulture.com/2018/05/stephanie-beatriz-bisexual-awakening-on-screen-and-off.h

tml. Accessed 31 March 2020.

UK Local Government Act 1988, Section 28.

http://www.legislation.gov.uk/ukpga/1988/9/section/28/1991-02-01 Accessed 13 Mar. 2020.

McGrady, Meg and Morris, Zoe Elle. “Sex Education" song accompanies The Phase Musical, ‘Our Journey to Beam 2020’ YouTube. 27 Mar. 2020.

https://www.youtube.com/watch?v=YDJYgtc9i7Y Accessed 31 Mar. 2020.

Meyer, Ilan H. “Prejudice, Social Stress, and Mental Health in Lesbian, Gay, and Bisexual Populations: Conceptual Issues and Research Evidence." Psychological Bulletin, vol. 129, no. 5, 2003, pp. 674-97, doi:10.1037/0033-2909.129.5.674.

Miranda, Lin-Manuel. “Yeah. Read Those Letters Man.” Twitter @lin_manuel, 26 May 2015, https://twitter.com/lin manuel/status/602979552806187008?lang=en.

Office for National Statistics. “Sexual Orientation 2012 - 2018 UK Dataset." Office for National Statistics, UK Government, 3 June 2020, https://www.ons.gov.uk/peoplepopulationandcommunity/culturalidentity/sexuality /datasets/sexualidentityuk.

Whitfield, Sarah K. "Putting Bisexuals in 'The Room Where it Happens': the Hamilton fandom's fight for bisexual+ representation' in Theatre Fandom ed by Kirsty Sedgman, University of Iowa Press (forthcoming, 2021), series: Fandom \& Culture series eds. Paul Booth \& Kathy Larsen. 
